\title{
THE BIONIC DESIGN AND SYSTEM IDENTIFICATION OF INTELLIGENT BIONIC LEG WITH MAGNETO-RHEOLOGICAL DAMPER
}

\author{
Hua-Long Xie, Nan He, Fei Li, Jian-Yu Yang
}

Original scientific paper

Intelligent bionic leg (IBL) controlled by magneto-rheological (MR) damper is an advanced prosthesis. The structure of human knee joint and torque control methods of IBL knee joint are analysed. The bionic design of IBL with MR damper is introduced. The transfer function of IBL is gained by system identification and parameter tuning of PID control based on genetic algorithm is done. The combined control simulation based on PID method indicates that IBL with MR damper can track the normal gait of human healthy leg well. The transfer function can describe IBL system characteristics well and parameter tuning of PID control based on genetic algorithm is effective.

Keywords: intelligent bionic leg; parameter tuning; PID control; system identification

\section{Bionička konstrukcija i identifikacija sustava inteligentne bioničke noge s magneto-reološkim prigušivačem}

Izvorni znanstveni članak

Inteligentna bionička noga (IBL) upravljana magneto-reološkim (MR) prigušivačem predstavlja usavršenu protezu. Analizira se konstrukcija zgloba koljena kod čovjeka i metode reguliranja zakretnog momenta zgloba koljena IBL-a. Predstavlja se bionička konstrukcija IBL-a s MR prigušivačem. Prijenosna funkcija IBL-a postiže se identifikacijom sustava i podešavanjem parametara PID upravljanja na temelju genetičkog algoritma. Kombinirana simulacija upravljanja na osnovu PID metode pokazuje da IBL s MR prigušivačem može dobro oponašati normalan način hoda zdrave noge. Prijenosna funkcija može dobro opisati karakteristike IBL sustava i učinkovito je podešavanje parametara PID upravljanja na temelju genetičkog algoritma.

Ključne riječi: identifikacija sustava; inteligentna bionička noga; podešavanje parametara; PID upravljanje

\section{Introduction}

In the process of human social development, it has led to a lot of people with physical disabilities as a result of natural disasters, accidental injury, traffic accident and war, and many other factors. The $2^{\text {nd }}$ national sampling investigation of the disabled indicates that there are at least 24120 thousand people with physical disabilities in China and about 440 thousand lower limb amputees [1]. In the US, around 1,6 million people live with limb loss. About $97 \%$ of all vascular limb loss are lower-limb amputations, of which $25,8 \%$ are above-knee amputations [2]. As a civilized society, we have a responsibility to provide the necessary technical support for the life of these people. Intelligent bionic leg which is close to human healthy leg both in appearance and function is an advanced prosthesis [3, 4]. It could maximum functionally simulate and approach the motion trajectory of human leg.

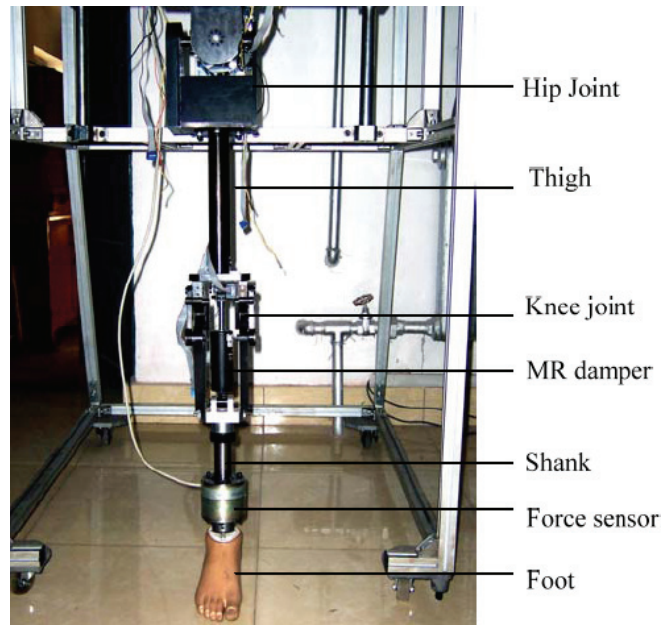

Figure 1 The prototype of IBL
The prototype of IBL developed by robotics project group at Northeastern University, China, is shown in Fig. 1. Its structure includes hip joint, thigh, bionic knee joint, shank and flexible prosthetic foot. Prosthetic foot is fixed to shank and ankle joint has no degree of freedom. The bionic knee joint is semi-controlled by MR damper to adjust rotation performance. MR damper can provide biggish damper force and lesser resilience to insure IBL track human natural gait well. Six-axis force sensor is used to detect the information of ground reaction force (GRF).

The control of IBL can boil down to a real-time trajectory tracking problem of natural instability, strong coupling, nonlinear and flexible system [5]. Its tracking target is the change curve of knee flexion angle with time and control object is MR damper of knee joint.

\section{Bionic design of IBL \\ 2.1 Mechanism design of knee joint}

The knee joint bears the largest weight and is the most complex joint of human body. Its main movement is flexion and extension. The structure of knee joint is directly related to the bionic characteristics and kinematic performance of IBL. The reasonable structure of knee joint can guarantee the stability in support phase and flexibility in swing phase. According to previous research of biomedicine [6], the human knee joint is composed of irregular shape of bones which are connected by ligament. The main bone structure of knee joint includes the femur, tibia and patella. Due to combined action of anterior cruciate ligament (ACL), posterior cruciate ligament (PCL), medial ligament, lateral ligament, joint capsule and tendons, knee joint can move freely without dislocation. The contact surfaces between femoral bottom 
and tibial top are irregular. During flexion and extension activity of knee joint, there are both rolling and sliding between the two contact surfaces. The outstanding feature of knee joint is that its instantaneous centre of rotation (ICR) is not fixed and is similar to a ' $\mathrm{J}$ ' curve, as shown in Fig. 2. Thus the length of thigh and shank is variable and the distance between foot and ground is increased.

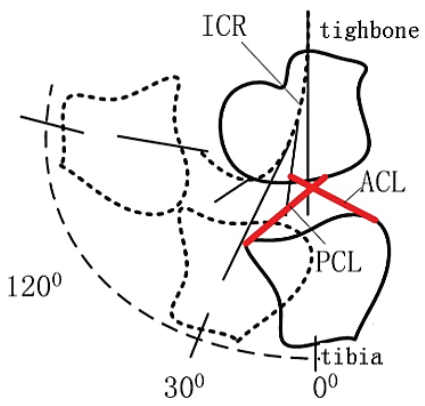

Figure 2 Human knee joint

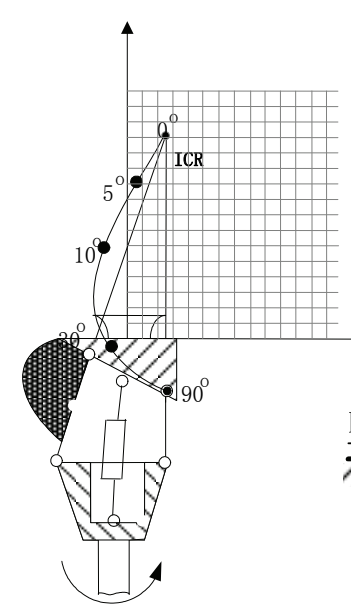

a. "J" curve of ICR

b. Higher foot clearance

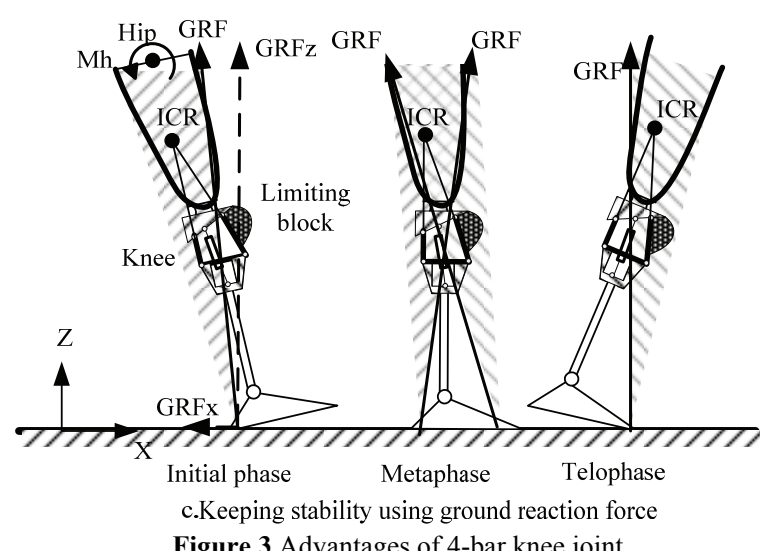

Now most of the humanoid robot and artificial limb joints adopt single axis knee mechanism and motor driver. Its rotation centre is fixed and has obvious difference from that of a human knee joint. Bionic knee joint should adopt multiple axis knee mechanism (4-bar, 5-bar and 6bar). The 4-bar bionic knee is adopted in the design of IBL because it has simple structure, low cost and excellent performance. Comparing with single axis knee mechanism, 4-bar closed-chain knee mechanism has many advantages such as 'J' curve of ICR [7], higher foot clearance and good stability with ground reaction force, as shown in Fig. 3.

\subsection{Driving selection of knee joint}

The torque control of knee joint is very crucial for the development of IBL. In the existing torque devices, the constant friction is the simplest one. However, the constant torque value does not meet changes of torque requirements during whole gait cycle. Hydraulic damping device can greatly improve the torque during swing phase and the damping force can be increased when walking speed increases. But its structure is complex and machining precision is high. Pneumatic damping device can overcome the shortcoming of these two devices and is widely used. However, its volume is generally large and the available torque is limited, thus its function is limited.

With the development of computer technology, microelectronics and materials science, intelligent driving devices, such as ER damper, MR damper, artificial muscle and shape memory alloy appear. MR damper is considerable potential for semi-active control and has a series of advantages, such as simple structure, small volume, smart response, low energy consumption, large resistance etc. The biomedical research indicates that semi-active control of knee joint has advantages of active joint and passive joint. It matches biological mechanism of human leg well and is an ideal choice of IBL. Virtual prototype of IBL is shown in Fig. 4.

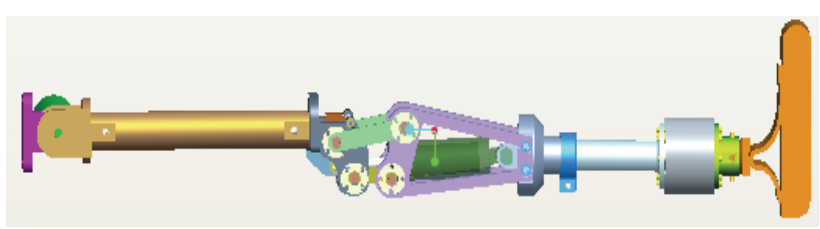

Figure 4 Bionic knee joint of IBL

\section{System identification of IBL}

The essence of system identification is to identify the mathematical model of the whole system based on the input/output time function. Its content mainly includes structure identification and parameter estimation. Normally structure identification and parameter estimation are intertwined. Based on the understanding of prior knowledge when modelling, normally the system model can be divided into three categories [8]: white box model, grey box model and black box model. The system model in this paper belongs to black box model, i.e. to the system model which can reflect system characteristics according to extracting information from input/output data under the condition of incomplete information.

\subsection{Identification data acquisition and pretreatment}

The identification data is obtained by establishing three-dimensional model of IBL, importing the established model into ADAMS and doing simulation experiments. The time domain analysis methods of transfer function identification mainly include: step response, impulse response method and rectangular pulse response, etc. Since a constant torque is applied on knee joint of IBL in this simulation experiment, the step response method of time domain analysis is adopted to complete the system identification. A $10 \mathrm{NM}$ torque is applied in the three-dimensional model and the simulation 
time is $0,5 \mathrm{~s}$. The swing angles of IBL knee joint are obtained as a basis for system identification. Parts of the input/output data are shown in Tab. 1.

Table 1 Part of torque-angle data

\begin{tabular}{|c|c|c|}
\hline Num & Input / NM & Output / \\
\hline 0 & 10 & 3,290277 \\
\hline 1 & 10 & 3,290470 \\
\hline 2 & 10 & 3,291044 \\
\hline 3 & 10 & 3,292002 \\
\hline 4 & 10 & 3,293343 \\
\hline 5 & 10 & 3,295067 \\
\hline 6 & 10 & 3,297176 \\
\hline 7 & 10 & 3,299670 \\
\hline 8 & 10 & 3,302550 \\
\hline 9 & 10 & 3,305817 \\
\hline 10 & 10 & 3,309471 \\
\hline 11 & 10 & 3,313514 \\
\hline 12 & 10 & 3,317946 \\
\hline 13 & 10 & 3,322770 \\
\hline 14 & 10 & 3,327987 \\
\hline 15 & 10 & 3,333597 \\
\hline 16 & 10 & 3,339604 \\
\hline 17 & 10 & 3,346007 \\
\hline 18 & 10 & 3,352810 \\
\hline 19 & 10 & 3,360013 \\
\hline 20 & 10 & 3,367620 \\
\hline 21 & 10 & 3,375631 \\
\hline
\end{tabular}

Due to the identification data is gained from threedimensional model simulation based on software ADAMS, its integrity and reliability are good and do not need too much pretreatment work. The identification process requires the characteristics of input/output data have nothing to do with the starting point of time. The mean value of the data should be zero and the detected input/output data should be filtered. The system input/output curve is shown in Fig. 5. The input and output are driving moment and rotation angle of knee joint respectively.
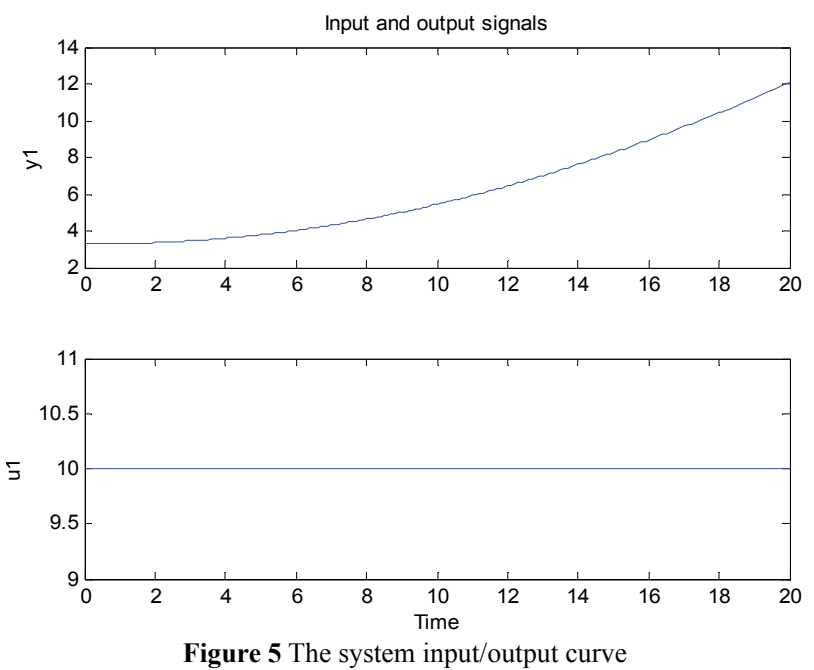

The actual measurement data obtained is stochastic time series which has a linear or slow change trend. It should be preprocessed which mainly includes filter and elimination of data trend. The input and output curve after filtering is shown in Fig. 6.
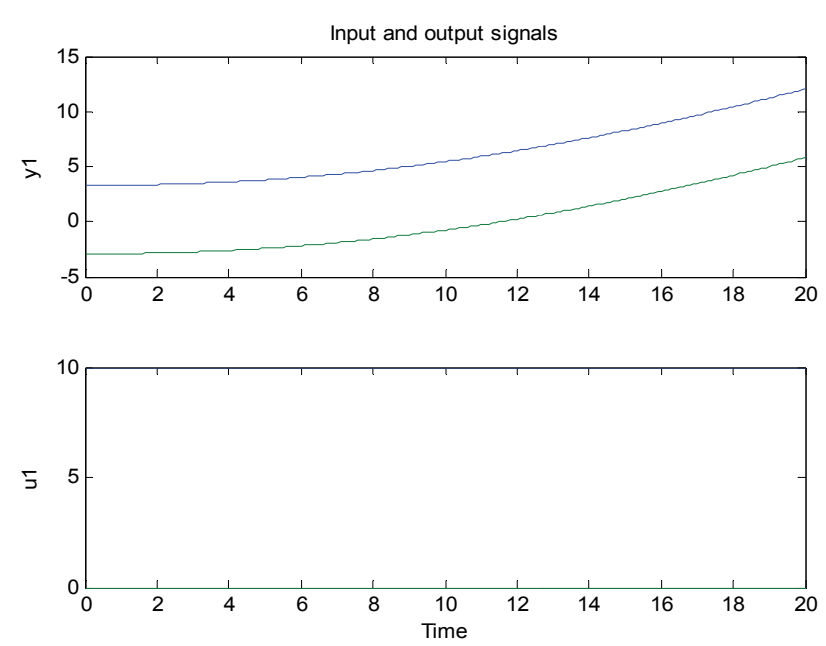

Figure 6 Input/output curve after filtering (green)

\subsection{The extraction and analysis of system priori knowledge}

The priori knowledge is very important to the selection of model structure, experiment design and decision of identification method. If the system response has small time delay and self-balance performance, its response curve can adopt transfer function model of second order self-balance object for system identification. The transfer function of second order self-balance object can be written as follows:

$$
G(s)=\frac{K e^{-t s}}{\left(T_{1} s+1\right) \cdot\left(T_{2} s+1\right)} .
$$

The response curve of second order self-balancing object is shown in Fig. 7. The system response curve of IBL gained by simulation experiment agrees well with that of second order self-balance object. Since the system response has small time delay and self-balance performance, the transfer function model of second order self-balance object is used for system identification in the paper.

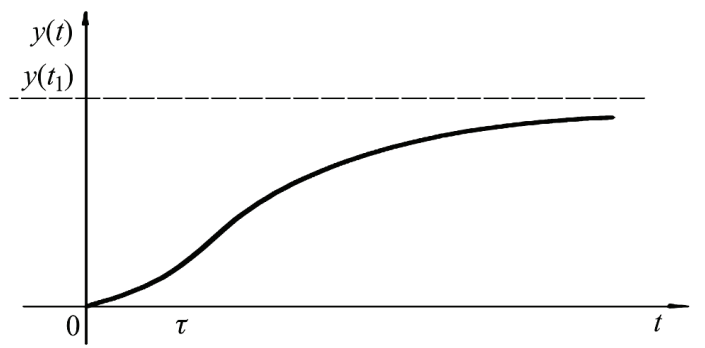

Figure 7 The response curve of second order self-balancing object

\subsection{The model selection and parameter estimation}

The ARX and process model of MATLAB tool box are adopted in system identification. The structure of ARX model can be written as follows:

$A\left(z^{-1}\right) Y(k)=B\left(z^{-1}\right) U(k)+e(k)$.

where $U \in R^{n} u$ and $Y \in R^{n} y$ are system input/output; $e \in R^{n} y$ is white noise; $z^{-1}$ is backward shift operator. 
The classical methods of parameter identification include the least square method, the auxiliary variable method, maximum likelihood method and time-varying parameter method, etc. The basic idea of above methods is derived from the least squares method whose equations for the discrete random system can be written as follows:

$$
\begin{aligned}
& z(k)+a_{1} z(k-1)+\ldots a_{n a} z(k-n a)= \\
& =b_{1} u(k-1)+b_{2} u+\ldots+b_{n b} z(k-n b)+e(k),
\end{aligned}
$$

where $z(k)$ is the observation value of system output at the $k$ time; $u(k)$ is the system input value at the $k$ time; $e(k)$ is the random noise whose mean value is zero. The identification results with four kinds of model are shown in Fig. 8.

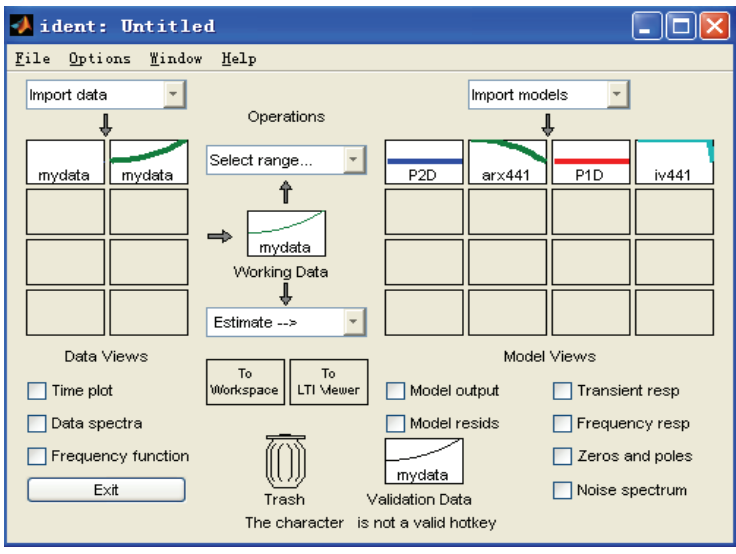

Figure 8 Identification results with four kinds of model

The comparison of actual output and the fitting model output is shown in Fig. 9. Since the following performance and integrality of $\mathrm{P} 2 \mathrm{D}$ model is well, the P2D model is adopted to approximate IBL model in the paper.

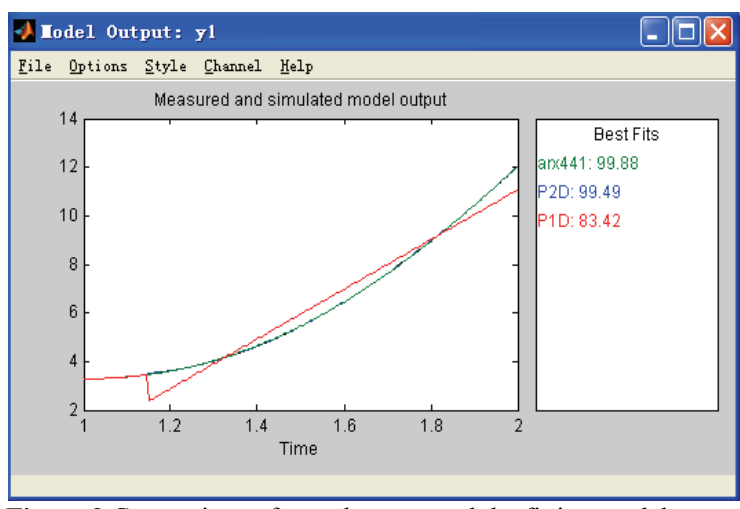

Figure 9 Comparison of actual output and the fitting model output

The model parameters of IBL after identification are shown in Fig. 10.

The identified transfer function with P2D model can be written as follows:

$$
G(s)=\frac{21,635}{7,733 \cdot s^{2}+7,23 \cdot s+1} \cdot \mathrm{e}^{-0,15 s} .
$$

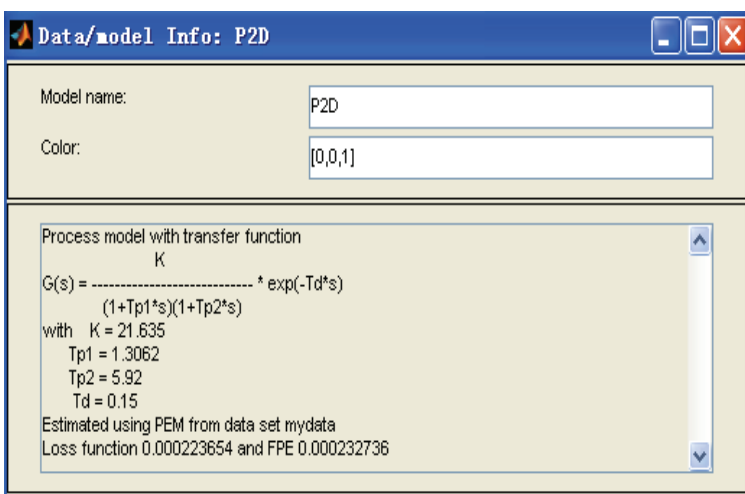

Figure 10 Model parameters of IBL after identification

\section{PID parameters tuning based on genetic algorithm}

PID control is the earliest developed and the most widely used control strategy in industrial process control. It mainly includes three parts control of proportion, integral and differential based on feedback principle. PID control method has advantages of simple principle, strong adaptability and robustness, etc. Even if the mathematical model of controlled object is not precise, it can also be used. The control law of PID method can be written as follows:

$u(t)=k_{p}\left[e(t)+\frac{1}{T_{i}} \int_{0}^{t} e(t) d t+T_{d} \frac{d e(t)}{d t}\right](5)$

Its transfer function can be written as follows:

$G(s)=k_{p}\left[1+\frac{1}{T_{i} s}+T_{d} s\right]$

where $k_{p}$ is proportionality coefficient; $T_{i}$ is integral time constant; $T_{d}$ is differential time constant. The parameters $k_{p}, T_{i}$ and $T_{d}$ can be timely tuned according to the dynamic characteristics of the process.

Commonly, PID parameter tuning adopts empirical formula or trial and error method, result in the effect not very ideal and inefficient. Genetic algorithm mimics biological evolution process of natural selection and evolution mechanism, and it is a global optimization algorithm based on a random group. Even under the condition of the object model uncertainty, the parameters of $k_{p}, T_{i}, T_{d}$ can be optimized according to the output of the object.

The sampling time is $0.1 \mathrm{~s}$ and the system input is the first step signal. In order to obtain satisfactory dynamic characteristics, the integral of absolute value of system input/output error is selected as objective function of parameters tuning. The square of system input is introduced in objective function to avoid control variable too large. The objective function can be written as follows:

$J=\int_{0}^{\infty}\left(\varpi_{1}|e(t)|+\varpi_{2} u^{2}(t)\right) \mathrm{d} t+\varpi_{3} t_{u}$ 
where $u(t)$ is the system output; $e(t)$ is the system error; $t_{u}$ is rise time; $\omega_{1}, \omega_{2}, \omega_{3}$ are the weighting. In order to avoid overshoot, penalty function is adopted. When $e(t)<0$, the objective function can be written as follows:

$J=\int_{0}^{\infty}\left(\omega_{1}|e(t)|+\omega_{2} u^{2}(t)+\omega_{4}|e(t)|\right) \mathrm{d} t+\omega_{3} t_{u}$.

During the whole process, the turning process is encoded using MATLAB based on genetic algorithm. The number of samples used in genetic algorithm is 30 . The crossover and mutation probability are 0,9 and 0,033 respectively. The parameter values of $\omega_{1}, \omega_{2}, \omega_{3}, \omega_{4}$ are 0,$999 ; 0,001 ; 2,0$ and 100 respectively. The optimized parameter values obtained by real number encoding and 100 evolution are shown as follows:

$k_{p}=0,6733, k_{d}=0,7145, k_{i}=0,0952$.

The optimization result of objective function is shown in Fig. 11. The step response after PID tuning is shown in Fig. 12.

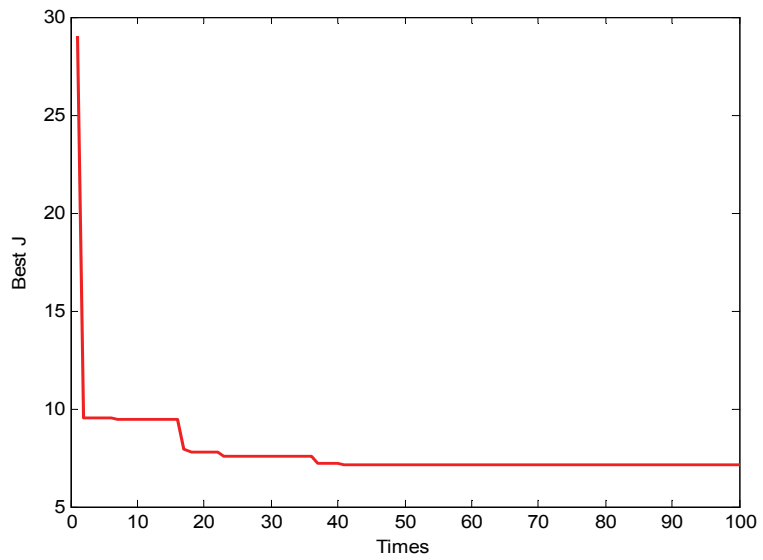

Figure 11 Optimization result of objective function

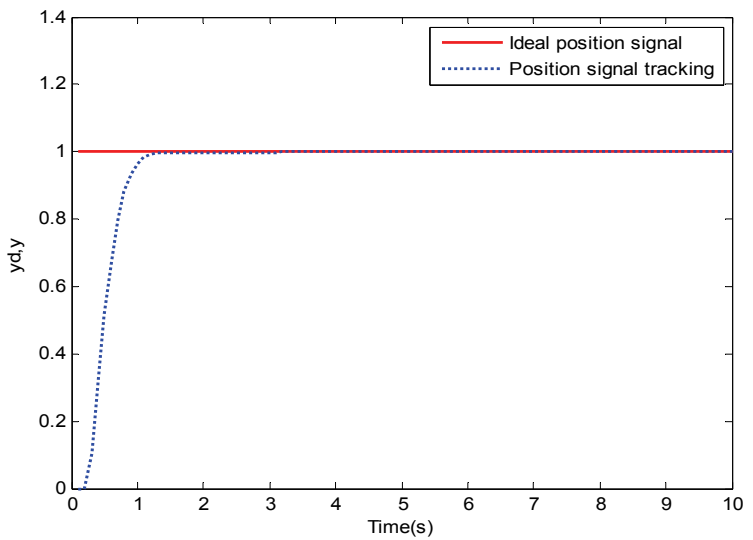

Figure 12 The step response after PID tuning

\section{Control simulation of knee joint}

To verify the control performance of IBL, the combined control simulation based on PID method is done using software Pro/E, ADAMS and MATLAB Simulink. The system characteristic of IBL is described by transfer function and the input is control torque of knee joint obtained above. The PID parameter has been tuned based on genetic algorithm. In consideration of the difference between actual and ideal angles of knee joint existing, the previous output error is specified as system feedback to adjust the next input and ensure the consistency between actual gaits and ideal gaits of knee joint. The control simulation model of IBL knee joint based on PID method can be shown in Fig. 13. The gait tracking of knee joint is shown in Fig. 14. The tracking error is shown in Fig. 15.

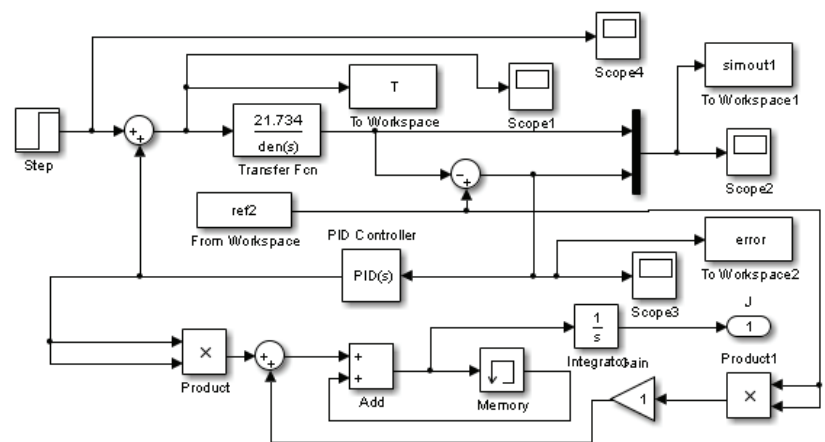

Figure 13 The control simulation model of IBL knee joint based on PID method

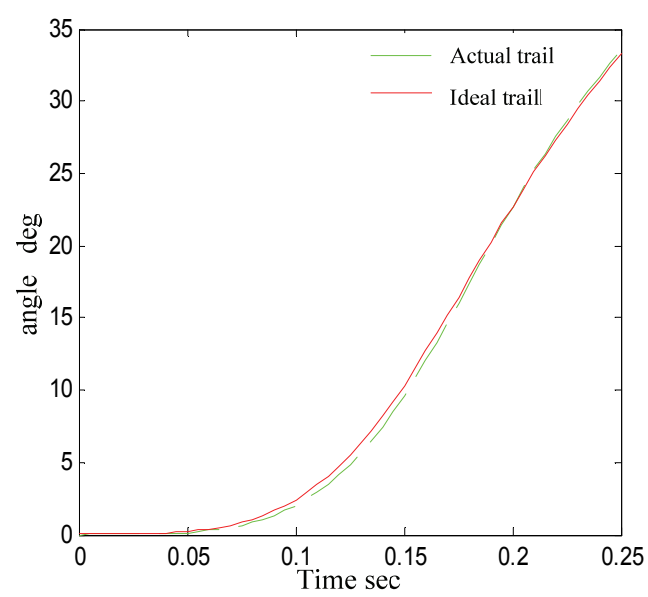

Figure 14 Gait tracking of IBL knee joint

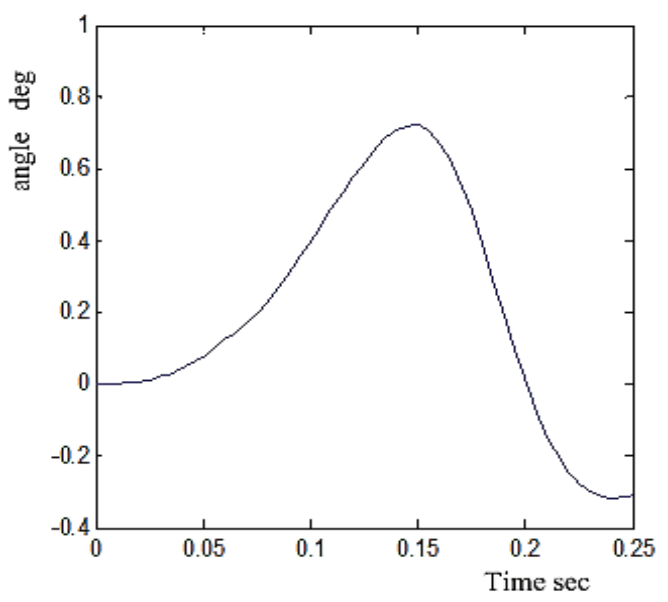

Figure 15 Tracking error of IBL knee joint

The combined control simulation indicates that the PID control with parameter tuning based on genetic algorithm has good control effect to the gait tracking of knee joint. The method based on system identification is 
better than that of dynamic modelling which is complex and time-consuming.

Generally, the target system is always simplified as a rigid system, and the dynamics model established on the basis of this rigid system cannot fully reflect the true system characteristics. Furthermore, the dynamic modelling is very complex even if the system is simple. System identification can rationally simplify some problems in absence of the kinematics and dynamics model of the object. It can well reflect the system characteristics of IBL knee joint with single input/output.

\section{Conclusions}

Intelligent bionic leg is a new-style application area of MR damper. Using 4-bar bionic knee joint, IBL has alterable ICR, reliable stability and higher foot clearance with ground. The transfer function gained by system identification can describe IBL system characteristics well and PID parameter tuning based on genetic algorithm is effective. The simulation indicates that IBL with MR damper can track the normal gait of human healthy leg well and the PID control based on parameter tuning has good effect.

\section{Acknowledgements}

Financial supports from National Natural Science Foundation of China (ID 51105070), the Fundamental Research Funds for the Central Universities (ID N120403002) and Scientific Study Project of Liaoning Province Education Department (ID L2013048 and L2013118) are highly appreciated. Also thanks the supports from Basic Research Project of Key Laboratory of Liaoning Province Education Department (ID LZ2015037) and the Fundamental Research Funds for the Central Universities (ID N140305001).

\section{References}

[1] Xie, H. L.; Kang, G. C.; Li, F. The Design and Control Simulation of Trans-femoral Prosthesis Based on Virtual Prototype. // International Journal of Hybrid Information Technology. 6, 6(2013), pp. 91-100. DOl: 10.14257/ijhit.2013.6.6.08

[2] Ziegler, G. K.; MacKenzie, E. J.; Ephraim, P. L.; Travison, T. G.; Brookmeyer, R. Estimating the Prevalence of Limb Loss in the United States - 2005 to 2050. // Archives of Physical Medicine and Rehabilitation. 89, 3(2008), pp. 422429. DOI: 10.1016/j.apmr.2007.11.005

[3] Unal, R.; Behrens, S. M. et al. Prototype Design and Realization of an Innovative Energy Efficient Transfemoral Prosthesis. // International Conference on Biomedical Robotics and Biomechatronics, September 26-29, 2010, Tokyo, Japan. DOI: 10.1109/biorob.2010.5626778

[4] Pillai, M. V.; Kazerooni, H.; Hurwich, A. Design of a Semi-active Knee-ankle Prosthesis. // IEEE International Conference on Robotics and Automation, May 6-13, 2011, Shanghai, China. DOI: 10.1109/icra.2011.5980178

[5] Wang, B. R.; Xu, X. H. Study of intelligent bionic limb prosthesis. // Control and Decision. 19, 2(2004), pp. 121133.
[6] Breakey, J. W. Theory of integrated balance: The lower limb amputee. // Journal of Prosthetics and Orthotics. 10, 2(1998), pp. 42-44. DOI: 10.1097/00008526-199801020-00006

[7] Amador, B. T.; Torrealba, R. R.; Rojas, M. et al. Metodología para dimensionamiento de mecanismopolicéntrico de rodillautilizandoanálisis de marcha y algoritmosgenéticos. // Revista Ingeniería Biomédica. 6, 11(2012), pp. 30-45.

[8] Wang, X. D.; Wei, M.; Zhao, J. W. et al. Parameter Identification Based on System Identification Toolbox in Matlab. // Journal of Ordnance Engineering College. 20, 4(2004), pp. 75-78.

\section{Authors' addresses}

Hua-Long Xie; Nan He; Jian-Yu Yang

School of Mechanical Engineering \& Automation, Northeastern University,

No. 3-11, Wenhua Road, Heping District Shenyang, Liaoning, 110819, P. R. China

E-mail: hlxie@mail.neu.edu.cn

Fei $\mathrm{Li}$

School of Information Science \& Engineering, Shenyang University of Technology,

Shenyang, Liaoning, 110870, P. R. China 